\title{
On the Occurrences of Critical Waves and Water Levels in the Venice Lagoon: A Statistical Analysis for the Management of the Operativity of the Mose System
}

\section{Giuseppe Tomasicchio ( $\nabla$ giuseppe.tomasicchio@unisalento.it)}

EUMER, Department of Engineering for Innovation, University of Salento; Lecce, Italyartment of Engineering Innovation: Universita del Salento Dipartimento di Ingegneria dell'Innovazione

\section{Gianfausto Salvadori}

Department of Mathematics and Physics, University of Salento; Lecce, ItalyUniversity of Salento: Universita del Salento

\section{Letizia Lusito}

EUMER, Department of Engineering for Innovation, University of Salento; Lecce, Italy

\section{Antonio Francone}

Polytechnic University of Bari Department of Civil Environmental Land and Construction Engineering and Chemistry: Politecnico di Bari Dipartimento di Ingegneria Civile Ambientale del Territorio Edile e di Chimica

\section{Ferdinando Frega}

University of Calabria Department of Civil Engineering: Universita della Calabria Dipartimento di Ingegneria Civile

\section{Alessandra Saponieri}

EUMER, Department of Engineering for Innovation, University of Salento; Lecce, Italy

\section{Elisa Leone}

EUMER, Department of Engineering for Innovation, University of Salento; Lecce, Italy

\section{Samuele De Bartolo}

EUMER, Department of Engineering for Innovation, Unviersity of Salento; Lecce, Italy

\section{Research Article}

Keywords: Venice lagoon, MoSE, Return period, Failure probability, Copulas, Significant wave height, Water level, Flood management, Lock gate

Posted Date: September 15th, 2021

DOI: https://doi.org/10.21203/rs.3.rs-879325/v1 
License: (c) (i) This work is licensed under a Creative Commons Attribution 4.0 International License. Read Full License

Version of Record: A version of this preprint was published at Stochastic Environmental Research and Risk Assessment on November 15th, 2021. See the published version at https://doi.org/10.1007/s00477021-02133-7. 


\title{
ON THE OCCURRENCES OF CRITICAL WAVES AND WATER LEVELS \\ IN THE VENICE LAGOON: A STATISTICAL ANALYSIS \\ FOR THE MANAGEMENT OF THE OPERATIVITY OF THE MOSE SYSTEM
}

\author{
Giuseppe R. Tomasicchio ${ }^{1, *}$, Gianfausto Salvadori ${ }^{2}$, Letizia Lusito ${ }^{1}$, Antonio Francone ${ }^{3}$, \\ Ferdinando Frega ${ }^{4}$, Alessandra Saponieri ${ }^{1}$, Elisa Leone ${ }^{1}$ and Samuele De Bartolo ${ }^{1}$ \\ ${ }^{*}$ Corresponding author: giuseppe.tomasicchio@unisalento.it
}

${ }^{1}$ EUMER, Department of Engineering for Innovation, University of Salento; Lecce, Italy

${ }^{2}$ Department of Mathematics and Physics, University of Salento; Lecce, Italy

${ }^{3}$ Department of Civil, Environmental, Land, Construction and Chemistry Engineering, Polytechnic of Bari; Bari, Italy

${ }^{4}$ Department of Civil Engineering, University of Calabria; Arcavacata di Rende, Italy

\section{Abstract}

The particular structure and configuration of the Venice lagoon represents a paramount case study concerning coastal flooding which affects natural, historical/cultural properties, together with industrial, commercial, economical and port activities. In order to defend Venice (and other sites) within the lagoon from severe floods, the Italian Government promoted the construction of a complex hydraulic/maritime system, including a movable storm surge barrier named Experimental Electromechanical Module (MoSE), to be activated when specific water levels occur. When the MoSE barriers are raised, the only access to the lagoon for commercial and cruise ships is represented by the Malamocco lock gate, provided that suitable safety conditions (involving the significant wave height) are satisfied. In addition, the Italian Government has recently established that, in the near future, large ships will_always have to enter/exit the lagoon only through the Malamocco gate. In turn, the navigation within the Venice lagoon is (will be) controlled by the combined MoSE-Malamocco system, ruled by both univariate and bivariate paradigms/guidelines. As a novelty, in the present work, for the first time, the statistics of significant wave heights and water levels in the Venice lagoon (both univariate and bivariate ones) are investigated: in particular, these variables turn out to be dependent, and their joint occurrence (statistically modeled via Copulas) can determine the stop of ship navigation, yielding significant economic losses. Here, univariate and bivariate Return Periods 
and Failure Probabilities are used to thoroughly model the statistical behavior of significant wave heights and water levels, in order to provide useful quantitative indications for the management of the tricky hydraulic, maritime and economical system of the Venice lagoon.

Keywords: Venice lagoon, MoSE, Return period, Failure probability, Copulas, Significant wave height, Water level, Flood management, Lock gate.

\section{Introduction}

The Venice lagoon is located in the northern Adriatic Sea and is characterized by a surface area of about $550 \mathrm{~km}^{2}$, a length of about $52 \mathrm{~km}$, and a width ranging from $8 \mathrm{~km}$ to $14 \mathrm{~km}$ (Figure 1). The lagoon's surface area is composed by $8 \%$ of land, including the city of Venice and other smaller islands, and by $92 \%$ of dredged channels, mud flats and salt marshes. The lagoon is separated from the Adriatic Sea by a strip of land made up of Pellestrina, Malamocco, and Lido islands, and presents three entrances: Chioggia, Malamocco, and Lido. Beside famous historical and residential sites, several of which are UNESCO World Heritage sites (http://www.veniceandlagoon.net/web/en/), an international airport, a cruise port in Venice, and a large industrial area with an important commercial port (Marghera) are located in the lagoon. 


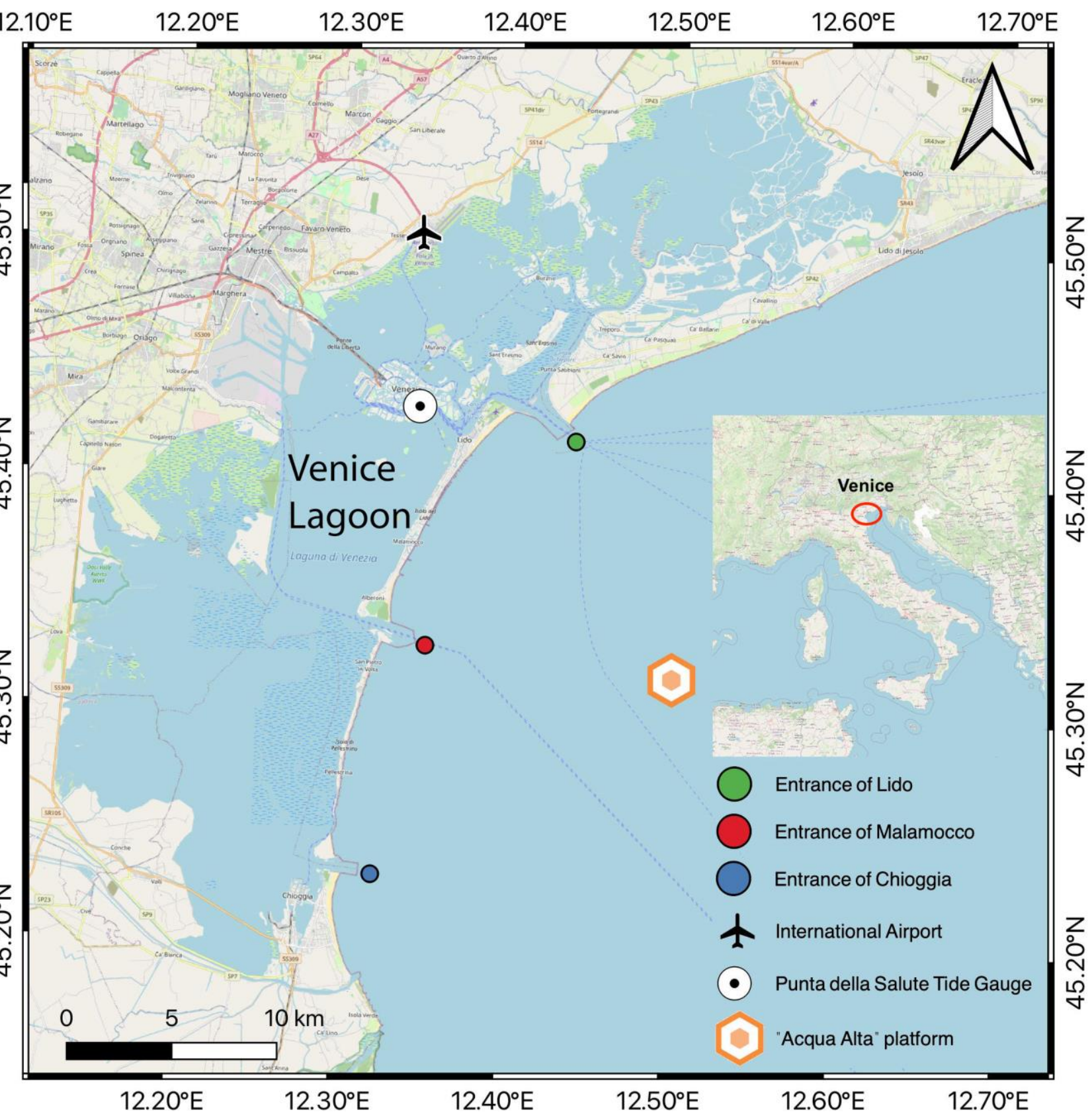

Figure 1. Map of the Venice lagoon

53 Venice lagoon is a fragile environment with natural, cultural and historical properties often subjected

54 to flooding; in addition, there are industrial, commercial, touristic (e.g., cruise market) and port

55 activities/economy to be preserved. Over the past 60 years, the Venice lagoon has experienced several

56 flooding events. On November $4^{\text {th }}, 1966$, the Venice lagoon suffered from the largest observed water

57 level $(W L)$ with $+1.94 \mathrm{~m}$ with respect to the "Punta della Salute" Mareographic Zero (MZPS) ${ }^{1}$. As a

\footnotetext{
${ }^{1}$ https://www.comune.venezia.it/it/content/riferimenti-altimetrici (in Italian)
} 
58 further recent example (Figure 2), the "Acqua Alta ${ }^{2}$ " event that happened on November $13^{\text {th }}, 2019$

59 was characterized by a maximum water level of +1.87 m MZPS at "Punta della Salute", and occurred

60 with a delay of about one hour after the peak of $+1.82 \mathrm{~m}$ observed at the Italian National Research

61 Council (CNR) platform, also named “Acqua Alta” (Figure 1).

62

63

64

65

66

67

68

69

70

71

72

73

74



Figure 2. November $13^{\text {th }}$, 2019. Flooding of Venice (source: Il Bo Live - UNIPD newspaper)

Since 1872, 21 overall "Acqua Alta" events exceeded the level +1.40 m MZPS, which is considered exceptional. In particular, during the periods 1984-2019 and 2011-2019, an average of 5.5 and 8.5 “Acqua Alta" events per year, respectively, has been observed (Canestrelli et al., 2001). Future predicted sea level rise will very likely increase the frequency of flooding (Jongman et al., 2012; Tomasicchio et al., 2018; Carbognin et al., 2010).

Storm surge events in the Venice lagoon are more frequent and characterized by higher water levels than in other parts of the Mediterranean basin due to the presence of shallow waters with a large continental shelf, and to the effect of the Sirocco and Bora winds (Robinson et al., 1973; Pirazzoli,

\footnotetext{
2 The "Acqua Alta" (literally, "High Water") happens when San Marco square in Venice (+ 0.82 m MZPS) is flooded.
} 
2002; Trigo, 2002; Lionello, 2005). In addition, flooding events are exacerbated by the lowering of ground surface due to local anthropogenic subsidence (e.g., extraction of gas from the subsoil), sediment compaction, glacial isostatic adjustment (small) and long-term tectonic vertical motion.

To defend the Venice lagoon from severe floods, the Italian Government promoted the construction of a complex hydraulic/maritime system which includes a movable storm surge barrier named Experimental Electromechanical Module (MoSE), to be closed during specific sea state conditions (see later) to protect the low areas behind it against flooding (Figure 3). The MoSE barrier is composed of bottom-hinged floating gates able to temporarily isolate the Venice lagoon from the Adriatic Sea during critical storm surge events, thus protecting the low areas of Venice against flooding, ensuring acceptable safeguarding water levels in Venice. Specifically, together with other measures (e.g., coastal reinforcement, raising of quaysides, lock gates for ships transit during the surge barrier closure, rubble mound breakwaters), the MoSE is expected to protect Venice from floods of up to $3.0 \mathrm{~m}$ MZPS, although UNESCO notices that this threshold is likely to be overcome more frequently and for longer periods of time in the future (UNESCO, 2020).
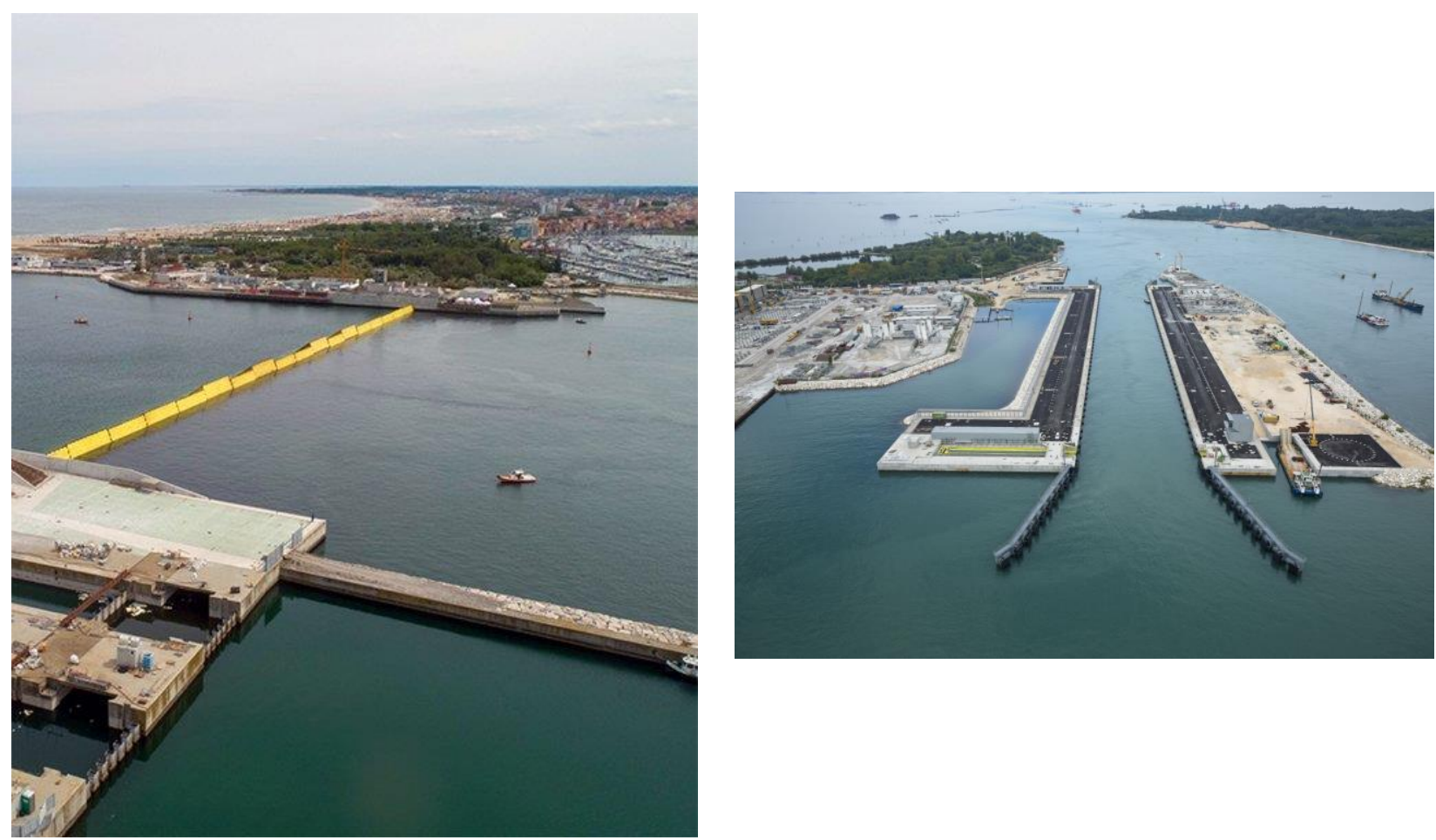

Figure 3. (Left) The MoSE barrier raised (yellow structure). (Right) The lock gate of Malamocco. 
91 The raise of the MoSE barriers is regulated by a complex normative, based on so-called "risk classes"

92 (Consorzio Venezia Nuova, 2005; Eprim et al., 2005; Cavallaro et al., 2017). In the present work we consider, as a reference, the "B1 CV" class criterion, the most extreme one concerning the so-called "frequent events" (i.e., with a Return Period less than 10 years, viz. the "normal" situation), corresponding to a Water Level of $0.75 \mathrm{~m}$ measured at the "Punta della Salute/Canal Grande" tide gauge, which would trigger the rise of the MoSE barriers. A further access to the lagoon is represented by the Malamocco lock gate (Figure 1 and Figure 3). However, it can be used by ships to enter/exit the lagoon only if a port pilot is able to get on/off board, and this is possible only if the Significant Wave Height $\left(H_{s}\right)$ measured at the CNR platform “Acqua Alta" (Figure 1) is less than $2.7 \mathrm{~m}$ (Deltares, 2016). As a consequence, the analysis of the conditions that may prevent the navigation within the lagoon involves both univariate and bivariate paradigms, and require different methodologies. More precisely:

- it will be a univariate approach if the interest is in the rise of the MoSE barriers only, or in the impossibility of ship transit thorough (in/out) the Malamocco gate due to the lack of a port pilot on board;

- it will be a bivariate approach if the interest is in the "sealing" of the whole lagoon to the maritime traffic (i.e., both the MoSE barriers raised and the Malamocco lock gate useless due to the impossibility of a port pilot to get on/off board).

As explained below, the latter analysis will naturally involve a bivariate "AND" Hazard Scenario approach, corresponding to sea state conditions such that both the significant wave height and the to the maritime traffic. Concerning the Malamocco lock gate, closures due to accidental disruptions

113 or scheduled maintenance activities will not be considered. Incidentally, notice that the Italian 114 Government has recently established that, in the near future, cruise (or other large) ships will always 
115 have to enter/exit the lagoon only through the Malamocco entrance ${ }^{3}$ : in turn, the (statistical) study of

116 its possible "disruption" (univariate and/or bivariate) has become more and more fundamental.

117 It is interesting to note that recent research has focused on the analysis of Compound Events (CE),

118 i.e., multivariate occurrences in which the contributing variables may not be extreme themselves, but 119 their joint instances may nevertheless cause severe impacts: traditional univariate statistical analyses 120 cannot give information regarding the multivariate nature of CE's and the hazard/risks associated 121 with them (Schölzel and Friederichs, 2008; Bevacqua et al., 2017). Attention to CE's has also 122 increased at an international policy-makers level. In fact, the Intergovernmental Panel on Climate 123 Change (IPCC) notices that, in the coastal and inter-tidal zones, tides, waves and tidal surge events 124 can occur simultaneously, leading to increased flood severity, duration or frequency (IPCC, 2012). 125 Also at a European level, specific EU bottom-up networks have been created to carry on research 126 activities aimed at gaining a better understanding of CE's and at increasing awareness in coastal 127 communities about the inherent modelling challenges associated with CE's (e.g., the "DAMOCLES" 128 European COST Action \#CA17109). In a broad perspective, the present work deals with Compound 129 Events (via the Copula approach outlined below). Indeed, there are clear physical/economical 130 motivations for investigating the joint dynamics of wave heights and water levels, as they can generate 131 Compound Events critically impacting the Venice lagoon industrial, economical and port activities. 132 In the present work, the following topic concerning the operativity of the Venice lagoon port and 133 industrial activities is addressed: "To determine, in a probabilistically well-based and consistent way, 134 the Return Periods and the Failure Probabilities of the occurrences of wave heights and water levels 135 that could negatively affect the commercial activities in the Venice lagoon." Note that, here Failure 136 Probabilities are intended in a mathematical sense, i.e., as the probability of exceeding a limit sea 137 state within a given reference time period. As explained below, a Hazard Scenario simply represents 138 the situation in which the occurrences of wave heights and/or water levels could negatively impact

\footnotetext{
${ }^{3}$ https://www.governo.it/it/articolo/comunicato-stampa-del-consiglio-dei-ministri-n-10/16525
} 
139 industrial and port activities in the lagoon, and the Failure Probability is simply the probability that

140 the variables of interest take value in such a Hazard Scenario at least once within a given temporal 141 horizon (entailing the "Failure" of the commercial activities).

142 For this purpose, recent advances in Mathematics show how Copulas (Nelsen, 2006; Salvadori et al., 143 2007) represent an efficient tool to statistically investigate the joint behavior of dependent variables. 144 A thorough copula-based analysis (such as the one carried out in the present work) may provide 145 valuable estimates of the marginal and joint distributions useful for (multivariate) hazard assessment. 146 For a theoretical introduction to copulas see Nelsen (2006), Joe (2014) and Durante and Sempi 147 (2015); for a practical approach see Salvadori et al. (2007), Genest and Favre (2007), Salvadori and 148 De Michele (2007), De Michele et al. (2007) and Orcel et al. (2021).

149 Copulas have been already successfully applied in Maritime Engineering. In particular, Salvadori et 150 al. $(2014,2015,2020)$ and references therein, proposed a multivariate approach to the assessment of 151 the hazard based on copulas that can be applied to the design of coastal and offshore engineering 152 infrastructures. The copula-based approach may be alternative and complementary to those presented 153 in several papers available in Literature and is most suitable for modeling Compound Events 154 involving wave heights and water levels. The (statistical) analyses mentioned above, and carried out 155 in the present work, represent a novelty: actually, to the best of our knowledge, no similar studies are present in Literature concerning the Venice lagoon.

\section{Materials}

159 In this section, some basic information about the data used is presented.

\subsection{Wave height data set}

162 The available significant wave height $\left(H_{s}\right)$ data have been hourly observed at the CNR offshore 163 platform “Acqua Alta” (Figure 1) from 16/10/1987-12:00 to 31/12/2014-23:30. The research platform 164 was installed on January 1970 off the lagoon and is situated in $16 \mathrm{~m}$ deep water (ISMAR, 2020). 


\section{2.2. Water level data set}

167 The water level (WL) data set, covering the years 1987-2014, is part of the historical archive of the

168 "Centro Previsioni e Segnalazioni Maree" (Center for Tide Reports and Forecasts) of the city of

169 Venice ${ }^{4}$. Data were measured, at an hourly frequency, with respect to MZPS.

170

$171 \quad$ 2.3. Selection of the sea storms

172 As explained above, historical available data sets provide information about the wave height and the

173 water level. In order to avoid serial dependencies and correlations, in the present work an event-based

174 approach is used by adopting a maritime version of the Run Method outlined in Yevjevich (1967).

175 Practically, a sea storm starts when the significant wave height $H_{s}$ crosses upwards a given threshold $176 H_{0}$, and ends when $H_{s}$ persists below $H_{0}$ for at least $I_{0}$ hours. Figure 4 shows, as an example, a standard 177 Equivalent Triangular Wave Model used to identify sea storms (Boccotti, 2000).

178

\footnotetext{
${ }^{4}$ https://www.comune.venezia.it/node/6214 (in Italian)
} 


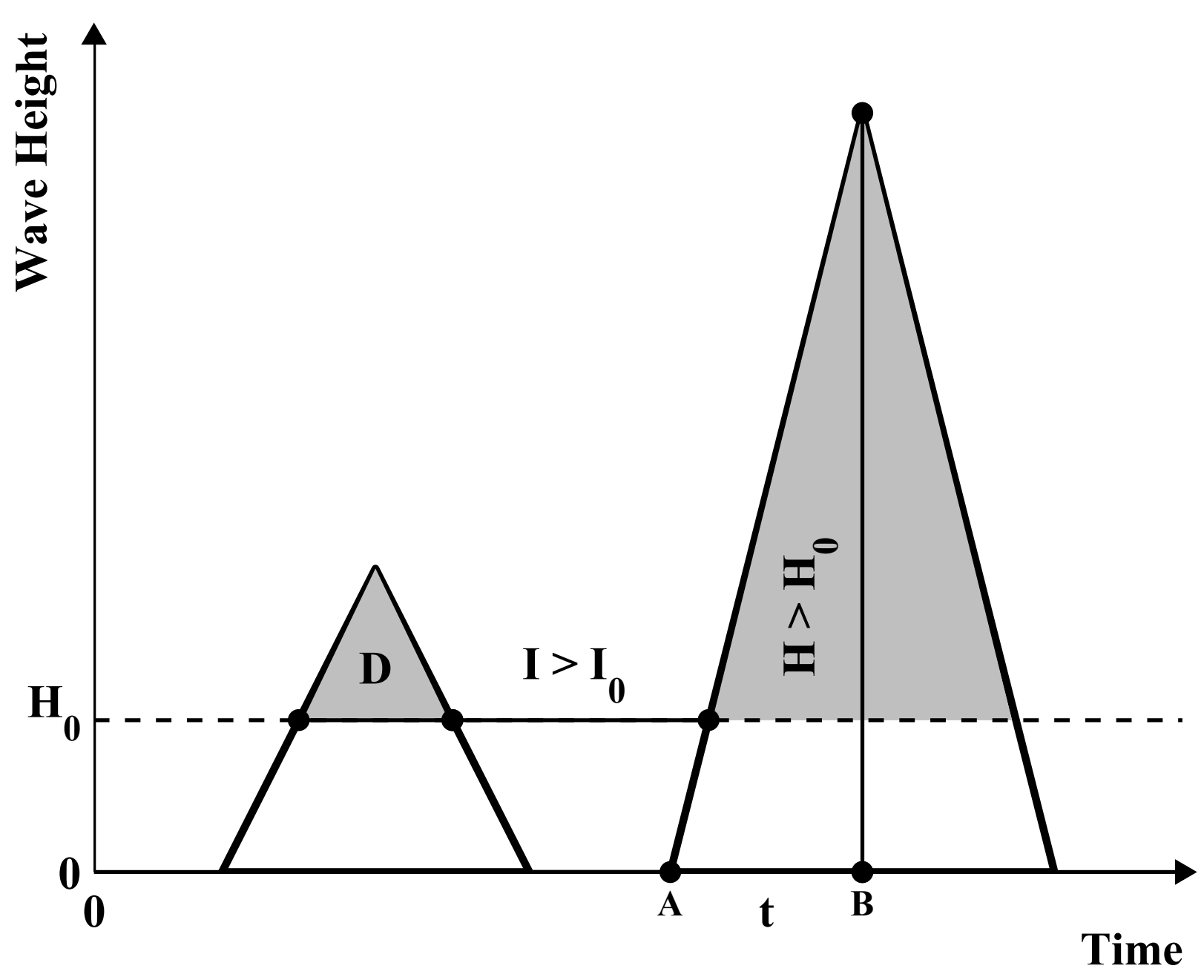

180 Figure 4. Sketch of the Equivalent Triangular Wave model used in the present work. Shown are: the significant wave

181 height threshold $H_{0}$, the event duration $D$, the inter-event period $I$ larger than the threshold $I_{0}$, a significant wave height $182 H$ larger than $H_{0}$, and the approximate duration $t$ of the climatic event generating the extreme wave (the temporal segment $183 A B^{-}$). The shaded regions indicate two successive triangular sea storms.

185 According to Davies et al. (2017) and Martzikos et al. (2021), here the threshold $H_{0}$ is taken as the $95^{\text {th }}$ percentile of the empirical distribution of wave heights. Also, a minimum inter-storm temporal distance $I_{0}=48 \mathrm{~h}$ is used to temporally separate successive sea storms: in fact, as indicated in Boccotti,

188 (2000) and Inghilesi (2000), this guarantees the physical meteo/marine independence of the events of 189 interest. Once over-threshold wave heights have been identified, the associated sea storm is 190 characterized by means of the maximum value of $H_{\mathrm{s}}$ observed during the event, as well as the 191 contemporaneous observed water level. In the present case, it turns out that a threshold $H_{0}=1.5 \mathrm{~m}$ 
should be used. The corresponding size of the sample of sea storms extracted, i.e., $N=520$, is large

193 enough for carrying out valuable statistical analyses. The extracted pairs $\left(H_{s}, W L\right)$ 's are presented in $194 \quad$ Figures 5 and 6.

Time series

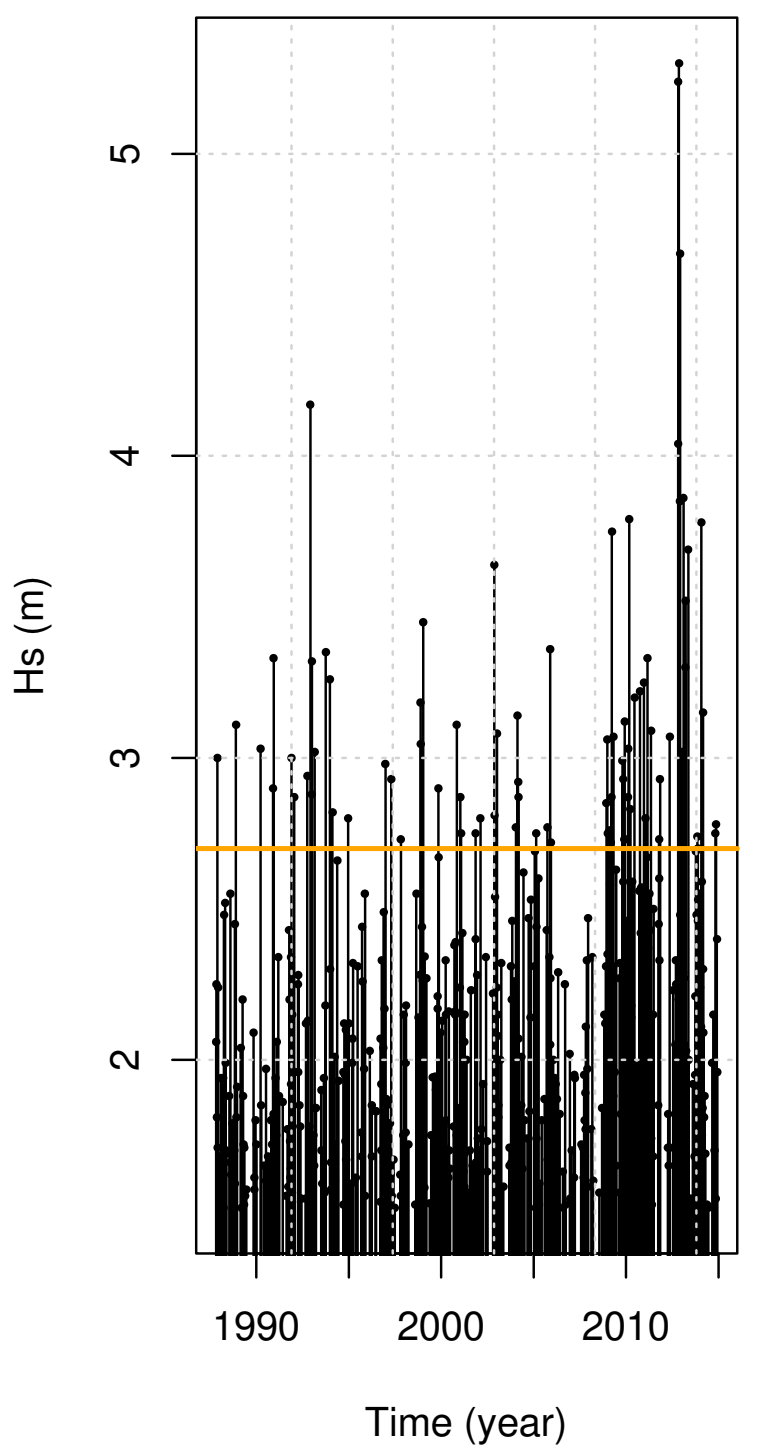

Time series

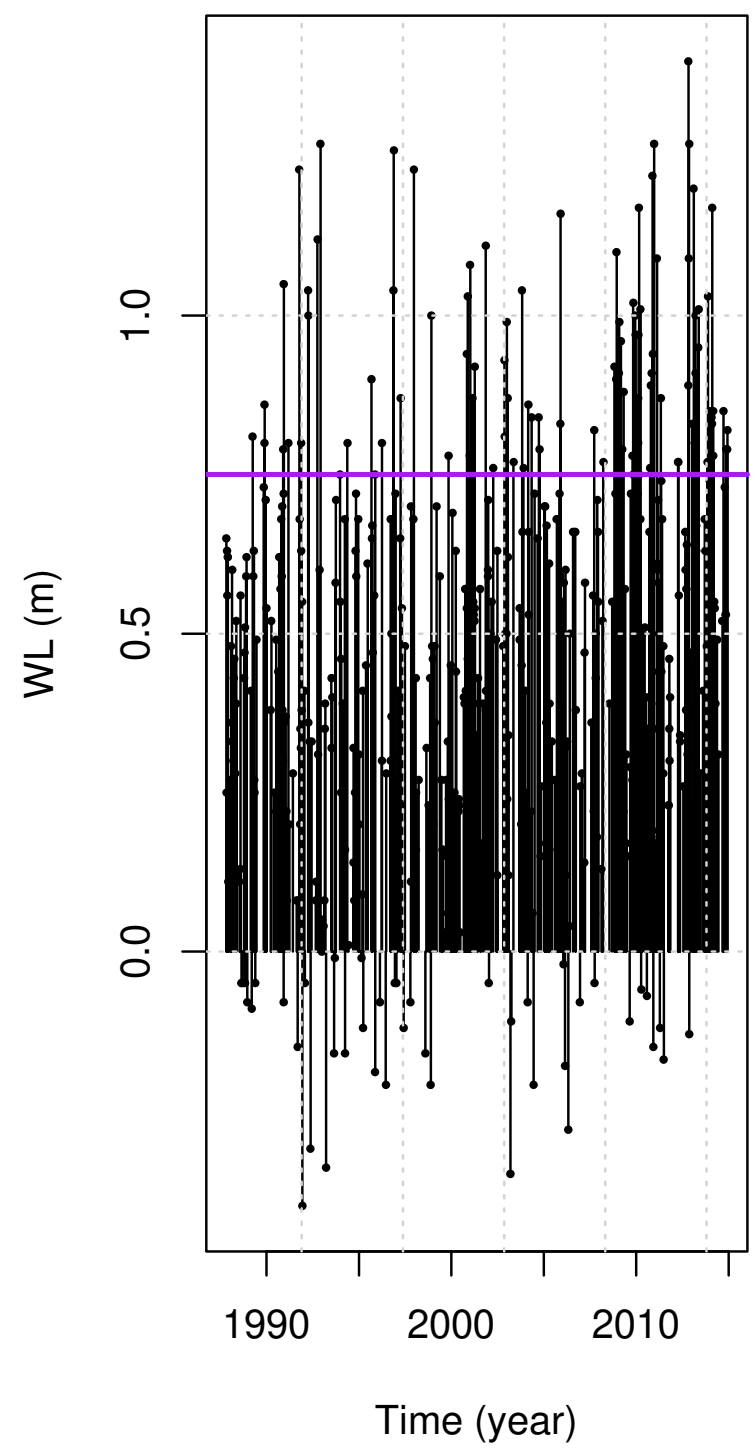

Figure 5. Time series of $H_{\mathrm{s}}$ (left) and $W L$ (right) data of the extracted sea storms. The colored horizontal lines indicate the critical thresholds mentioned in the Introduction: $2.7 \mathrm{~m}$ for $H_{\mathrm{s}}$ (orange) and $0.75 \mathrm{~m}$ for $W L$ (purple). 


\section{$(\mathrm{Hs}, \mathrm{WL})$ data}

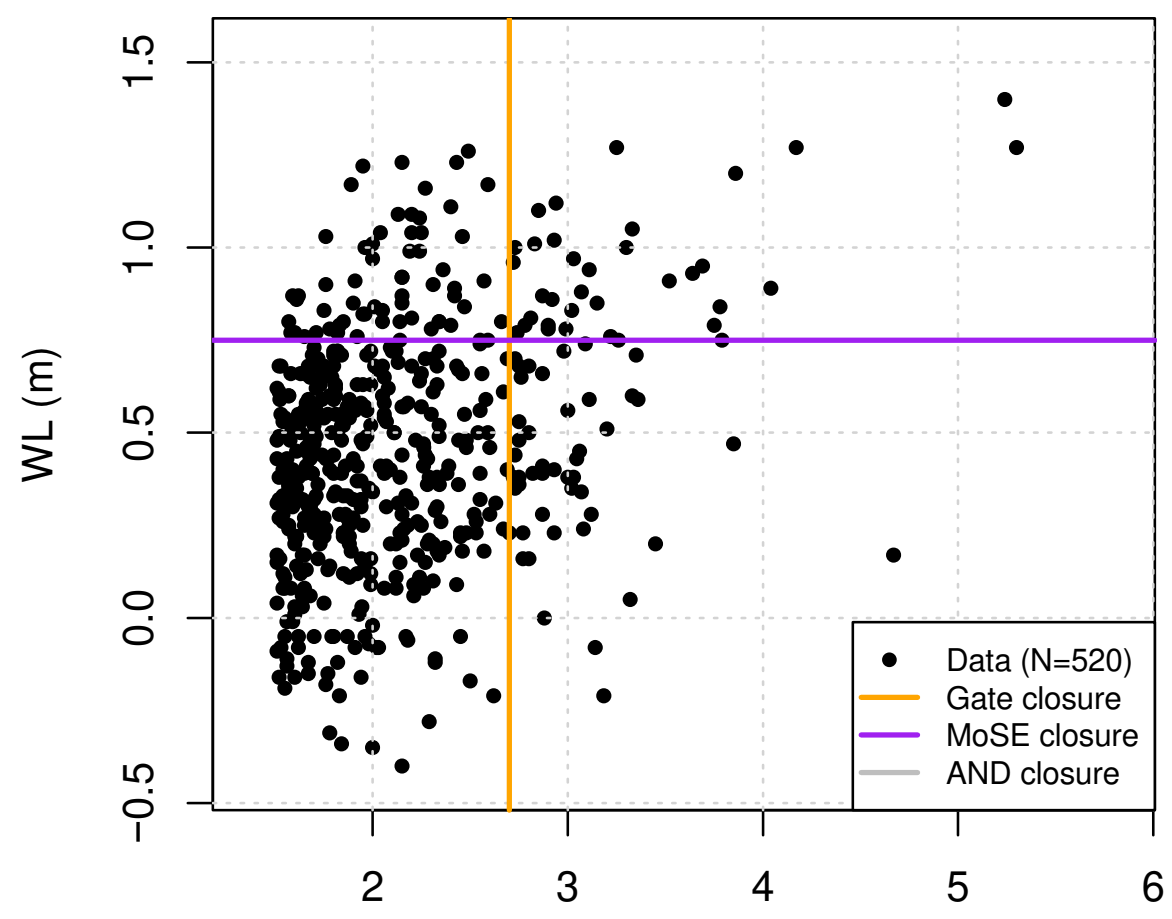

$\mathrm{Hs}(\mathrm{m})$

Figure 6. Plot of the extracted sea storms $\left(H_{\mathrm{s}}, W L\right)$ 's: also indicated is the sample size $N$. The orange and purple lines correspond to, respectively, the critical $H_{s}=2.7 \mathrm{~m}$ and $W L=0.75 \mathrm{~m}$ thresholds mentioned in the text. The gray shaded region is the "AND" Hazard Scenario used in the study-see text.

\section{Methods}

In the following, statistical information is extracted from sea storm data sets in terms of Return Periods $(R P)$ and Failure Probabilities $(F P)$, both in a univariate and in a bivariate framework. In particular, the analyses carried out in the present work exploit the notion of Hazard Scenario defined as follows (Salvadori et. al, 2016).

Definition 1 (Hazard Scenario - HS). Let $X=\left(X_{1}, \ldots, X_{d}\right)$ be a $d$-dimensional vector modeling

211 the phenomenon of interest. A Hazard Scenario (hereinafter, HS) of probability level $\alpha \in(0,1)$ is

212 any Upper Set $S=S_{\alpha} \subseteq R^{d}$ such that the following relation holds: 
214 where $S$ is an Upper Set if $x \in S$ and $y \geq x$ component-wise imply that also $y$ belongs to $S$.

215 In practice, here a HS is simply a set containing occurrences $x$ 's that may negatively affect the 216 commercial activities in the Venice lagoon. By the very definition of Upper Set, also $y$ could be 217 considered as a dangerous occurrence, since it "exceeds" $x$ in a component-wise sense.

218 In the univariate case, the HS of interest here is $\left\{X \geq x^{*}\right\}$, where a single critical threshold $x^{*}$ is 219 sufficient to individuate a hazardous region on the Real line. Instead, in the multivariate case, a 220 number of different HS's can be constructed (Salvadori et al., 2014; 2016). In the following, an 221 "AND" approach is used, for which the HS is given by $\left\{X>x^{*} A N D Y>y^{*}\right\}$ : this HS contains 222 bivariate $\left(H_{s}, W L\right)$ 's occurrences such that both $H_{s}$ and $W L$ exceed the respective critical thresholds mentioned above, corresponding to sea state occurrences that could prevent the navigation within the lagoon.

\subsection{Methods: Return Period}

In the following, the general notion of Return Period introduced in Salvadori et al. $(2004,2011)$ is adopted.

229 Definition 2 (Return Period). Given an event $E$, the associated RP $T_{E}$ is

$230 T_{E}=\mu / P(E)$,

231 where $\mu$ is the mean inter-arrival time between successive events $E$ 's in the considered time series.

232 Note that $\mu$ provides the time unit (e.g., years) in which $T_{E}$ should be expressed, and that a Hazard 233 Scenario corresponds to a specific event $E$ : in turn, it is possible to speak of Return Periods of HS's. 234 The above definition of $T_{E}$ is quite a general one, and can be used both for univariate and multivariate 235 events. More specifically:

236 - In case a univariate approach only based on the Wave Height $X$ is adopted, the corresponding $\mathrm{RP}$ is $T_{x^{*}}=\mu / P\left(X \in\left(x^{*}, \infty\right)\right)=\mu /\left(1-F_{X}\left(x^{*}\right)\right)$. Here the HS is $E=\left(x^{*}, \infty\right)$, where $x^{*}$ is 
a "critical" threshold for $X$ (e.g., the one prescribed by the Malamocco lock gate guidelines and operating rules).

- In case a univariate approach only based on the Water Level $Y$ is adopted, the corresponding RP is $T_{y^{*}}=\mu / P\left(Y \in\left(y^{*}, \infty\right)\right)=\mu /\left(1-F_{Y}\left(y^{*}\right)\right)$. Here the HS is $E=\left(y^{*}, \infty\right)$, where $y^{*}$ is a "critical" threshold for $Y$ (e.g., the one prescribed by the MoSE guidelines and operating rules).

- In case a bivariate approach is adopted, based on $X$ and $Y$, the "AND" RP $T_{A N D}$ of a bivariate event can be computed as:

$T_{A N D}=\mu /\left(1-F_{X}\left(x^{*}\right)-F_{Y}\left(y^{*}\right)+F_{X Y}\left(x^{*}, y^{*}\right)\right)$,

where $F_{X Y}$ is the joint distribution of the random vector $(X, Y)$. Here the HS is $E=\{X>$ $\left.x^{*} A N D Y>y^{*}\right\}$

Using the Theory of Copulas, according to Sklar's Theorem representation (Nelsen, 2006; Salvadori et al., 2007), the joint distribution function $F_{X Y}$ can be written as

$F_{X Y}\left(x^{*}, y^{*}\right)=P\left(X \leq x^{*}, Y \leq y^{*}\right)=C_{X Y}\left(F_{X}\left(x^{*}\right), F_{Y}\left(y^{*}\right)\right)=C_{X Y}\left(u^{*}, v^{*}\right)$

252 where $C_{X Y}:[0,1] \times[0,1] \rightarrow[0,1]$ is the bivariate copula of $(X, Y)$, i.e., the dependence structure of the random vector $(X, Y)$, and $F_{X}, F_{Y}$ are the corresponding marginal laws. In case $X$ and $Y$ were independent, then the joint distribution would become $F_{X Y}\left(x^{*}, y^{*}\right)=F_{X}\left(x^{*}\right) \cdot F_{Y}\left(y^{*}\right)=u^{*} v^{*}$, involving the so-called Independence Copula $C_{X Y}(u, v)=u \cdot v$. Note that Eq. (4) can be extended to a general multi-dimensional case.

\subsection{Methods: Failure Probability}

The computation of Return Periods represents a traditional source of information for design and hazard assessment of maritime structures (as well as of terrestrial ones). For the same purposes, a

261 further quantity of interest is represented by the notion of Failure Probability: this represents an 262 alternative and complementary way to achieve useful information from the available data. As 
263 already explained above, the Failure Probability does not represent the probability of a "structural"

264 collapse, rather it is simply the probability of observing an occurrence of the phenomenon of interest

265 in a prescribed Hazard Scenario at least once in a given temporal horizon.

266 In the present framework, let $T>0$ be an arbitrary temporal horizon: for the sake of simplicity, and 267 without loss of generality, $T$ is measured in years. Given $T$, and using as Hazard Scenario the "AND" 268 one introduced above, the corresponding FP's $p_{T}$ can be computed as in Salvadori et al. (2016) and 269 references therein:

$p_{T}=1-P\left(X \leq x^{*} \text { OR } Y \leq y^{*}\right)^{T}=1-\left(u^{*}+u^{*}-C_{X Y}\left(u^{*}, v^{*}\right)\right)^{T}$,

271 where $C_{X Y}$ is the bivariate copula of the pair $\left(H_{\mathrm{s}}, W L\right)$. Note that univariate FP's can be computed 272 in a similar way, simply using as a second term in the formula the probability that the variable 273 considered does not belong to the HS of interest.

\section{Results}

The main statistical features of the observed $H_{\mathrm{s}}$ and $W L$ data characterizing the sea storms of interest are shown in Table 1.

Table 1. Sample estimates of the main statistical features of the observed values of $H_{s}$ and $W L$ (in $m$ ).

\begin{tabular}{|l|l|c|}
\hline Parameter & $\boldsymbol{H}_{\boldsymbol{s}}$ & $\boldsymbol{W} \boldsymbol{L}$ \\
\hline Min & 1.51 & -0.40 \\
\hline Max & 5.30 & 1.40 \\
\hline Mean & 2.13 & 0.46 \\
\hline St. Dev. & 0.56 & 0.32 \\
\hline
\end{tabular}

\subsection{Univariate fits}

As a result, the Weibull distribution well fits the $H_{s}$ data, and the GEV law the $W L$ ones (Figure 7): here, the Maximum Likelihood technique is used to estimate the parameters of the distributions. The p-values of the Goodness-of-Fit (GoF) tests of Kolmogorov-Smirnov type are estimated via suitable 
Monte Carlo procedures, since the distributions are fitted on the data (Stephens, 1974). The null hypothesis is that the observed values of Hs and WL, respectively, are drawn from the Weibull and the GEV distributions. Since the corresponding p-values are all larger than $10 \%$, the null hypotheses cannot be rejected at standard levels (i.e., $1 \%, 5 \%$, and 10\%), and thus the fitted distributions can be accepted for modeling the statistics of Hs and WL. Actually, the fits look excellent also from a visual point of view.

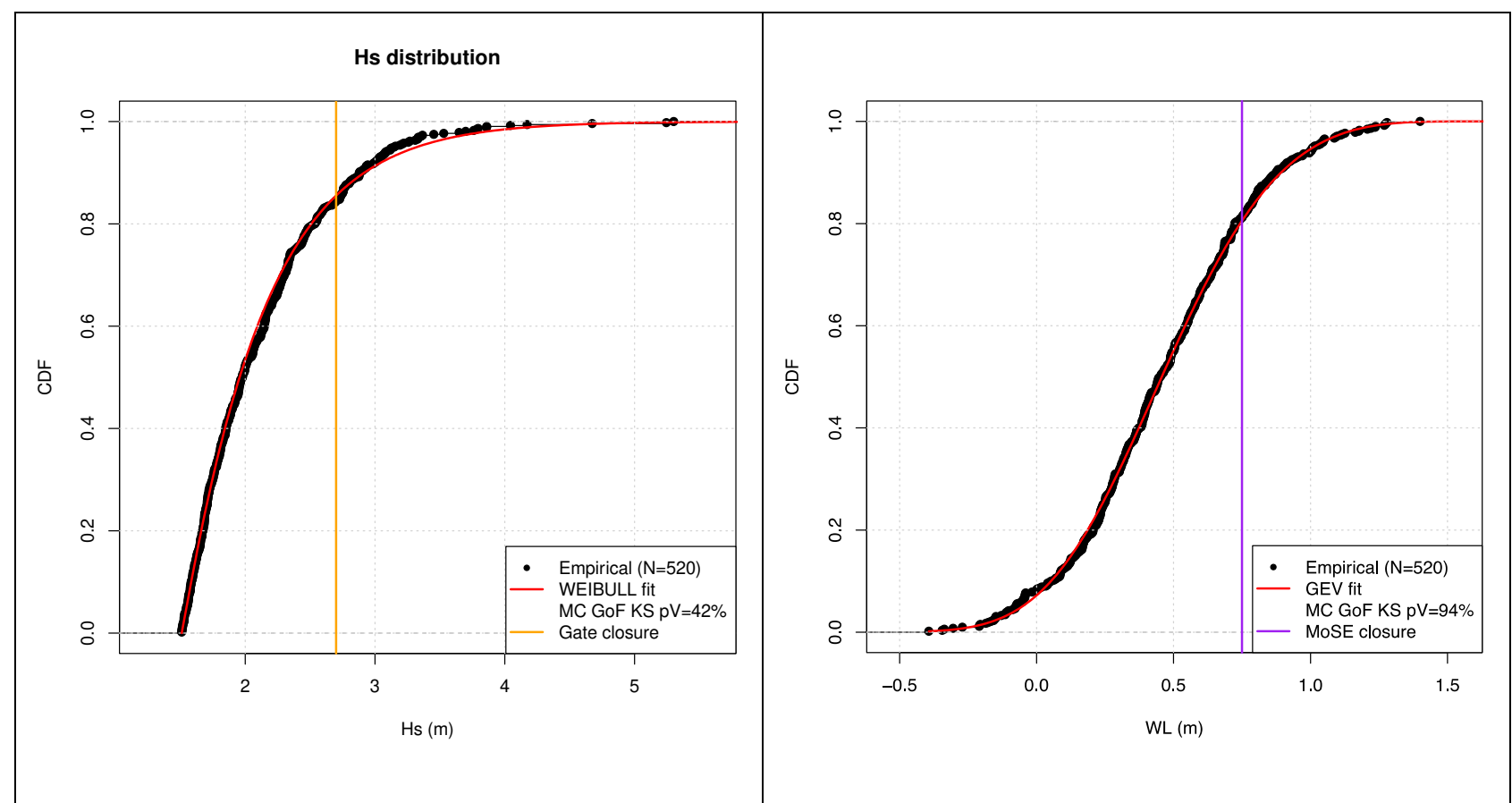

Figure 7. Fit of the $H_{s}$ (left) and $W L$ (right) data. Also indicated are the sample size $N$ and the Monte Carlo p-value of the KS GoF tests. The vertical orange and purple lines correspond to the thresholds for $H_{s}$ and $W L$ mentioned in the text, respectively.

\subsection{Copula fit}

297 The first step in any multivariate analysis consists in evaluating whether, and to what extent, two 298 variables are dependent. Traditionally, this is carried out by estimating the (non-parametric) Kendall $299 \tau$ and the Spearman $\rho$ statistics, as well as by performing the corresponding independence tests 300 (Nelsen, 2006; Salvadori et al., 2007). Should these parameters take a value statistically significantly 301 different from zero, then the variables would be dependent. Table 2 shows that $H_{s}$ and $W L$ are 302 statistically dependent (more precisely, concordant, for $\tau$ and $\rho$ are positive), since the p-values of 
the independence tests are negligible: in turn, a multivariate (copula) approach is mandatory, in order to correctly statistically model the joint behavior of the pairs $\left(H_{s}, W L\right)$ 's in the Venice lagoon.

Table 2. Estimates of the Kendall $\tau$ and the Spearman $\rho$ statistics, and corresponding p-values (in parentheses).

\begin{tabular}{|l|l|}
\hline Kendall $\boldsymbol{\tau}$ & Spearman $\boldsymbol{\rho}$ \\
\hline $0.18(6 \mathrm{e}-10)$ & $0.27(6 \mathrm{e}-10)$ \\
\hline
\end{tabular}

The available pairs $\left(H_{s}, W L\right)$ 's presented in Figure 6 cannot provide any information about the dependence structure (i.e., the Copula) that rules the joint random behavior of the variables. A correct way to get an idea of the copula at play (Nelsen, 2006; Salvadori et al., 2007) is to plot the so-called pseudo-observations, i.e., the ranks of the data normalized in the unit square (the domain of bivariate copulas): these are shown in Figure 8.

313 The bivariate dependence analysis has been carried out testing a dozen of copula families usually 314 adopted in the applications (as well as the corresponding Survival versions). These are used to fit 315 the dependence structure of the pair $\left(H_{s}, W L\right)$ : namely,

- [Archimedean]: Ali-Mikhail-Haq (AMH), Clayton, Frank, Gumbel, Joe

- [Elliptical]: Normal, $t$-Student $(t)$

- [Extreme Value]: Galambos, Husler-Reiss (HR), Tawn

- [Special] Farlie-Gumbel-Morgenstern (FGM), Plackett amounting to about twenty different dependence structures. In order to check the admissibility of a copula, a GoF test of Cramér-von Mises type is used, being more robust than the KolmogorovSmirnov one in the multivariate case (Genest et al., 2009): here the p-values are corrected for multiple comparisons (Hochberg and Tamhane, 1987). Then, among the dependence structures that pass the GoF test, a "best copula" is chosen via a traditional corrected Akaike Information Criterion (Akaike, 1974). 
326 As a result, the Husler-Reiss family statistically fits the $\left(H_{s}, W L\right)$ 's pairs, as shown in Figure 8.

327 Furthermore, it is interesting to note that the Husler-Reiss copula is an Extreme Value one, and thus

328 offers a possible paradigm for describing the extreme bivariate behavior of a phenomenon: in turn,

329 the statistical model constructed in the present work may provide useful hazard indications

330 concerning the instances of extreme bivariate $\left(H_{s}, W L\right)$ 's occurrences taking place at the lagoon,

331 potentially impacting economical activities. In addition, notice that the Independence copula shown

332 in Figure 8 is quite different from the empirical and the fitted ones, entailing that $H_{s}$ and $W L$ are

333 definitely dependent.

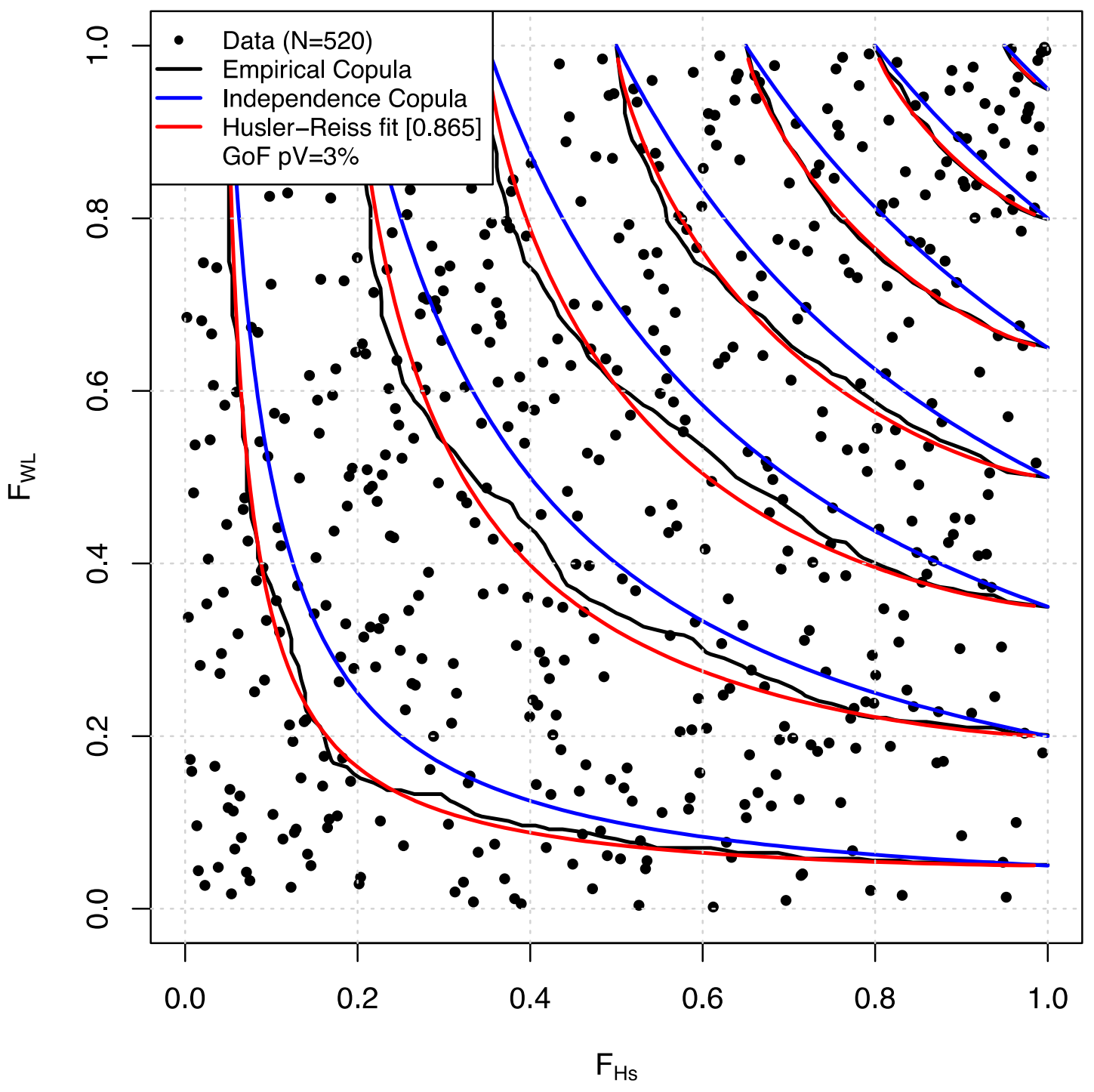


335 Figure 8. Fit of the Husler-Reiss Extreme Value copula (red isolines) over the $\left(H_{s}, W L\right)$ data: the black isolines are those of the Empirical copula, providing a non-parametric approximation to the dependence structure at play. Also indicated are the sample size $N$, the p-value of a Monte Carlo GoF test, and a Maximum Likelihood estimate of the copula parameter (in brackets). For the sake of comparison, the blue isolines are those of the Independence copula

\subsection{Calculation of Return Periods}

341 Once a critical bivariate reference occurrence $\left(x^{*}, y^{*}\right)$ has been fixed (which defines the Hazard 342 Scenario of interest), it is possible to estimate the associated RP's, both univariate and bivariate 343 ones, by using Eqs. (2)-(4). As prescribed by the guidelines and operating rules already mentioned 344 above, in the following, $\left(x^{*}, y^{*}\right)$ will be the vector $\left(H_{s}=2.7 \mathrm{~m}, W L=0.75 \mathrm{~m}\right)$, corresponding to 345 critical sea state conditions possibly entailing economical losses. The fits shown in previous 346 Sections provide the estimates of the probabilities of interest, i.e., $u^{*}=F_{X=H s}\left(x^{*}\right), v^{*}=$ $F_{Y=W L}\left(y^{*}\right)$, and $c^{*}=C_{X Y}\left(F_{X}\left(x^{*}\right), F_{Y}\left(y^{*}\right)\right)$ : these are reported in Table 3.

Table 3. Estimates of the probabilities $\mathrm{u}^{*}, \mathrm{v}^{*}$, and $\mathrm{c}^{*}$.

\begin{tabular}{|c|c|c|}
\hline $\boldsymbol{u}^{*}=\boldsymbol{F}_{\boldsymbol{X}=\boldsymbol{H} \boldsymbol{s}}\left(\boldsymbol{x}^{*}\right)$ & $\boldsymbol{v}^{*}=\boldsymbol{F}_{\boldsymbol{Y}=\boldsymbol{W L}}\left(\boldsymbol{y}^{*}\right)$ & $\boldsymbol{c}^{*}=\boldsymbol{C}_{\boldsymbol{X} \boldsymbol{Y}}\left(\boldsymbol{F}_{\boldsymbol{X}}\left(\boldsymbol{x}^{*}\right), \boldsymbol{F}_{\boldsymbol{Y}}\left(\boldsymbol{y}^{*}\right)\right)$ \\
\hline $85.5 \%$ & $80.6 \%$ & $72.1 \%$ \\
\hline
\end{tabular}

Table 4 shows the estimates of the RP's of closures, both univariate and bivariate ones. The label "AND" refers to the sealing of the Venice lagoon, the label "Gate" refers to the closure of the Malamocco gate due to the impossibility of a port pilot to get on/off board, and the label "MoSE" refers to the raise of the MoSE barriers. 
Table 4. Estimates (in days) of the RP's of closures: Monte Carlo 95\% Confidence Intervals are shown in parentheses.

\begin{tabular}{|c|c|c|}
\hline AND & Gate & MoSE \\
\hline 317.7 & 131.7 & 98.2 \\
\hline$(245.3,406.3)$ & $(112.8,159.0)$ & $(87.1,114.5)$ \\
\hline
\end{tabular}

360 Figure 9 shows the results of a Monte Carlo investigation concerning the uncertainties associated 361 with the RP's estimates: here, 1000 independent runs have been used.

\section{Closure return periods}

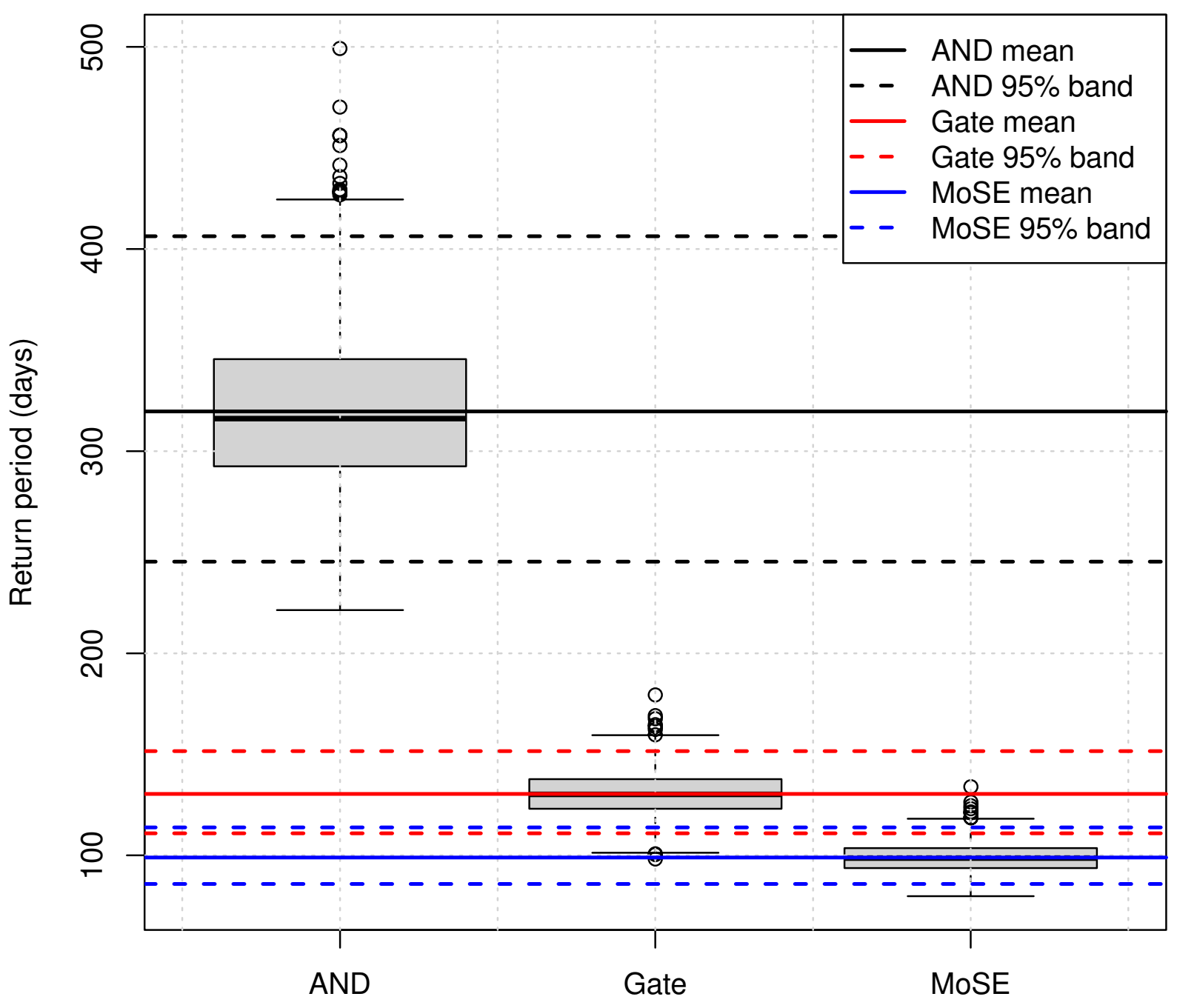

Data 
Figure 9. Boxplots of the Monte Carlo estimates of the RP's of closures. Also indicated are the Monte Carlo mean value estimates and the $95 \%$ Monte Carlo confidence intervals.

As a result, on average, the raise of the MoSE barriers is expected to be more frequent than the notransit circumstances through the Malamocco gate (about every 100 days against 130). Also, both the univariate closure RP's turn out to be smaller than the "AND" one. To the best of our knowledge, such quantitative outcomes are not available in Literature, and provide new (statistical) information concerning possible disruptions of the economical activities in the Venice lagoon. All of these practical estimates may be of great interest for the management and/or scheduling of the maritime traffic, also considering the recent directives of the Italian Government previously mentioned-

\subsection{Calculation of Failure Probabilities}

Given the critical pair $\left(x^{*}, y^{*}\right)$, the associated FP's can be computed by using Eq. (5): here, a temporal horizon $T=50$ years is used. Table 5 shows the estimates of the FP's of closures, both univariate and bivariate ones, for selected temporal horizons.

Table 5. Estimates of the Failure Probabilities of interest for selected temporal horizons $T$ (in years).

\begin{tabular}{|c|c|c|c|}
\hline $\boldsymbol{T}$ & AND & Gate & MoSE \\
\hline 1 & $6.0 \%$ & $14.5 \%$ & $19.4 \%$ \\
\hline 5 & $26.6 \%$ & $54.3 \%$ & $66.1 \%$ \\
\hline 10 & $46.2 \%$ & $79.1 \%$ & $88.5 \%$ \\
\hline 20 & $71.0 \%$ & $95.6 \%$ & $98.7 \%$ \\
\hline 30 & $84.4 \%$ & $99.1 \%$ & $99.9 \%$ \\
\hline 50 & $95.5 \%$ & $100 \%$ & $100 \%$ \\
\hline
\end{tabular}

As a quantitative result, fully consistent and coherent with the Return Period analysis, the "sealing" of the Venice lagoon (i.e., the "AND" case) is always less probable than the occasional partial closures due to the rise of the MoSE barriers or to the non-transit through the Malamocco lock gate. 
Figure 10 shows the results of a Monte Carlo investigation concerning the uncertainties associated

386 with the FP's estimates over the whole temporal horizon $T=50$ years: here, 1000 independent Monte 387 Carlo runs have been used. Overall, the confidence bands are narrow, and the univariate FP's 388 quickly converge to one, even for small T's. Evidently, for any given $T$, the probability of partial 389 closures (univariate perspective) is much larger than a global "sealing" of the Venice lagoon. Again, 390 these quantitative estimates may provide useful information concerning occurrences that could 391 negatively affect the commercial activities in the lagoon.

\section{Closure failure probabilities}

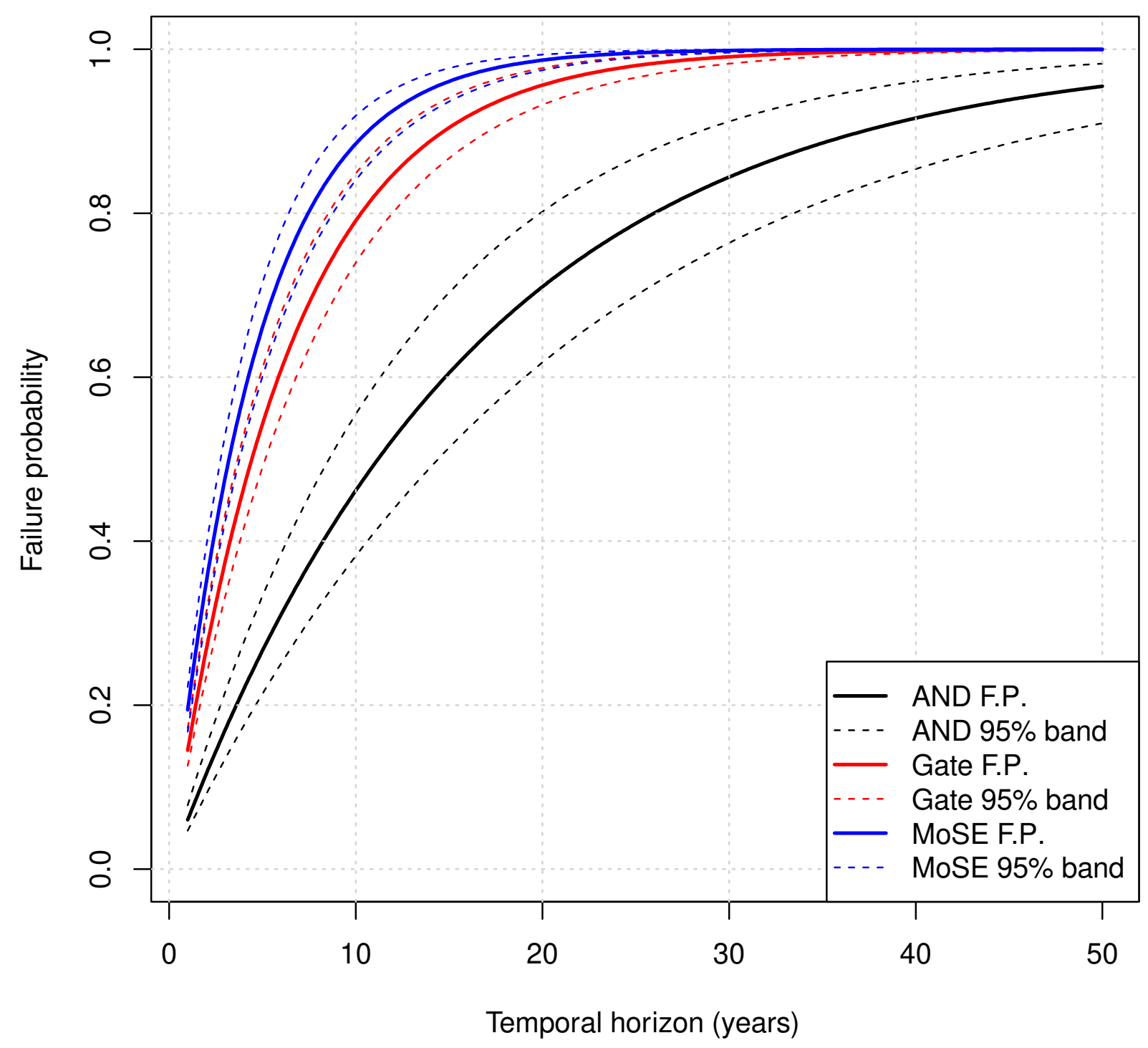


Figure 10. Failure Probabilities associated with univariate and bivariate approaches considering the available $\left(H_{s}, W L\right)$ data: the dashed lines represent 95\% Monte Carlo Confidence Bands.

\section{Conclusions}

The present work provides quantitative information about sea state conditions (both under univariate and bivariate perspectives) that could negatively impact the navigation within the Venice lagoon, potentially yielding huge economical losses. In particular, the following conclusions can be drawn.

- On average, the raise of the MoSE barriers is expected to be more frequent than the no-transit condition through the Malamocco gate (about every 100 days against 130). In addition, according to the the present bivariate analysis, univariate closure RP's are smaller than the "AND" ones. This latter quantitative calculation is only possible via a multivariate paradigm/approach.

- For any given temporal horizon $T$, the probability of partial closures (univariate perspective) is much larger than a global "sealing" of the Venice lagoon. For instance, for $T=20$ years, the estimated (closure) Failure Probabilities in the "AND" case is $71 \%$, for the Malamocco lock gate to be unusable is $95.6 \%$ and for the MoSE to be raised is $98.7 \%$ (see Table 5).

- The rates of partial and total closure of the Venice lagoon to the maritime traffic have been estimated (see Table 4), providing quantitative information about what should be expected concerning disruptions of the commercial activities in the lagoon.

The results obtained estimate (and quantitatively show) the non-negligible probability that the Venice lagoon could be practically isolated because both the MoSE barriers are raised $(W L>0.75$ $\mathrm{m})$ and the Malamocco lock gate is unusable because the port pilot cannot get on/off board of incoming/outcoming ships $\left(H_{s}>2.7 \mathrm{~m}\right)$. For the first time in Literature, the methodology outlined in the present paper is able to quantify such probabilities concerning the Venice lagoon case. This can help planning, in a more efficient and optimized way, all the activities related to the harbor/touristic ports, in turn improving the management of the operativity of the Venice lagoon. 
Moreover, in a more general perspective, the novel proposed approach, developed to contribute to

the engineering management of the complex system formed by the MoSE barriers and the Malamocco lock gate in the Venice lagoon, can straightforwardly be extended to the study of the operativity and the management of other tricky engineering systems.

\section{Acknowledgements}

The support of CMCC - Centro Euro-Mediterraneo sui Cambiamenti Climatici - Lecce (Italy) is acknowledged. The support of the European COST Action CA17109 "DAMOCLES" (Understanding and Modeling Compound Climate and Weather Events) is acknowledged. The support of the Italian PRIN 2017 (Research Projects of National Interest) "Stochastic Models of Complex Systems" [2017JFFHSH] is acknowledged. The support of Apulia Region, INNODUNECOST, POR Puglia

FESR FSE 2014-2020 - Sub-Azione 1.4.B, Contract n. RM5UKM2, is acknowledged.

\section{Competing interests}

The authors declare no competing interests.

\section{References}

Akaike, H. (1974). A new look at the statistical model identification. IEEE Transactions on Automatic Control 437 19, 6: 716-723.

438 Bevacqua, E., Maraun, D., Hobæk Haff, I., Widmann, M., and Vrac, M. (2017) Multivariate statistical modelling of compound events via pair-copula constructions: analysis of floods in Ravenna (Italy), Hydrol. Earth Syst. Sci., 21, 2701-2723, https://doi.org/10.5194/hess-21-2701-2017.

Boccotti, P. (2000) Wave mechanics for ocean engineering, vol. 64 of Elsevier Oceanography Series, Elsevier Science, Amsterdam.

Carbognin, L., Teatini, P., Tomasin, A. et al. (2010) Global change and relative sea level rise at Venice: what impact in term of flooding. Clim Dyn 35, 1039-1047. https://doi.org/10.1007/s00382-009-0617-5

Canestrelli, P., Mandich, M., Pirazzoli, P.A., Tomasin, A. (2001) Venti, depressioni e sesse: perturbazioni delle maree a Venezia (1950- 2001), Centro Previsioni e Segnalazioni Maree, Città di Venezia.

Cavallaro, L., Iuppa, C., Foti, E. (2017) Effect of Partial Use of Venice Flood Barriers, J. Mar. Sci. Eng. 5, 58. doi:10.3390/jmse5040058.

Davies, G., Callaghan, D.P., Gravois, U., Jiang, W., Hanslow, D., Nichol, S., Baldock, T. (2017) Improved treatment of non- stationary conditions and uncertainties in probabilistic models of storm wave climate. Coast. Eng. 127, 1-19. https://doi.org/ 10.1016/j.coastaleng.2017.06.005 
Deltares (2016) Wave conditions reaching the sea side of the Malamocco lock gates. Confidential report.

De Michele, C., Salvadori, G., Passoni, G., Vezzoli, R. (2007) A multivariate model of sea storms using copulas, Coastal Engineering 54, 734-751.

Durante, F., Sempi, C. (2015) Principles of copula theory, CRC/Chapman \& Hall, Boca Raton, FL.

Eprim, Y., Donato, M.D., Cecconi, G. (2005) Gates strategies and storm surge forecasting system developed forthe Venice flood management. In Flooding and Environmental Challenges for Venice and Its Lagoon: State of Knowledge; Cambridge University Press: Cambridge, UK, pp. 267-277.

Genest, C., Favre, A. (2007) Everything you always wanted to know about copula modeling but were afraid to ask, J. Hydrologic Engineering 12, 347-368.

Genest, C., Rémillard, B., Beaudoin, D. (2007) Goodness-of-fit tests for copulas: A review and a power study, Insurance: Mathematics and Economics 44, 2, pp. 199-213, https://doi.org/10.1016/j.insmatheco.2007.10.005.

Hochberg, Y. and Tamhane, A. (1987) Multiple Comparison Procedures. Wiley, New York.

Inghilesi, R., Corsini, S., Guiducci, F., Arseni A. (2000) Statistical analysis of extreme waves on the Italian coasts from 1989 to 1999. Boll. Geofis. Teor. Appl., 41, 3-4, pp. 315-337.

IPCC, (2012) Field, C.B., V. Barros, T.F. Stocker, D. Qin, D.J. Dokken, K.L. Ebi, M.D. Mastrandrea, K.J. Mach, G.-K. Plattner, S.K. Allen, M. Tignor, and P.M. Midgley (Eds.) Available from Cambridge University Press, The Edinburgh Building, Shaftesbury Road, Cambridge CB2 8RU ENGLAND, 582 pp. Available from June 2012

ISMAR (2020) http://www.ismar.cnr.it/infrastructures/piattaforma-acqua-alta?set_language=en\&cl=en

Italian Government. 2020. https://www.governo.it/it/articolo/comunicato-stampa-del-consiglio-dei-ministri$\underline{\mathrm{n}-10 / 16525 \text { (in Italian) }}$

Joe, H. (2014) Dependence Modeling with Copulas, CRC Monographs on Statistics \& Applied Probability, 474 Chapman \& Hall, London.

Jongman B., Ward P.J.J., Aerts J.C.J.H. (2012) Global exposure to river and coastal flooding: long term trends and changes. Glob Environ Change 22(4):823-835. https://doi.org/10.1016/j.gloenvcha.2012.07.004

Lionello P. (2005) Extreme storm surges in the Gulf of Venice: present and future climate. In: C. Fletcher, T. Spencer (Eds.), Venice and its lagoon, state of knowledge, Cambridge University Press, Cambridge.

Martzikos, N.T., Prinos, P.E., Memos, C.D., Tsoukala, V.K. (2021) Statistical analysis of Mediterranean coastal storms. Oceanologia, 63, 133-148.

481 Nelsen, R. (2006) An introduction to copulas, Springer-Verlag, New York, second edn.

Orcel, O., Sergent, P., and Ropert, F. (2021) Trivariate copula to design coastal structures, Nat. Hazards Earth Syst. Sci., 21, 239-260, 20211\%https://doi.org/10.5194/nhess-21-239-2021.

Pirazzoli, P.A. and Tomasin, A. (2002) Recent evolution of surge-related events in the Northern Adriatic area, Journal of Coastal Research 18, 3:537-554.

Robinson A.R., Tomasin, A., Artegiani, A. (1973) Flooding of Venice: phenomenology and prediction of the Adriatic storm surge, Quarterly Journal of Royal Meteorological Society 99, 688-692.

Salvadori, G., De Michele, C. (2004) Frequency analysis via copulas: theoretical aspects and applications to hydrological events, Water Resour. Res. 40, W12511. doi: 10.1029/2004WR003133.

Salvadori, G., De Michele, C., Kottegoda, N., Rosso R. (2007) Extremes in Nature. An approach using Copulas, vol. 56 of Water Science and Technology Library Series, Springer, Dordrecht. ISBN: 978-1-40204415-1.

Salvadori, G., De Michele, C. (2007) On the use of copulas in hydrology: theory and practice, J. Hydrol. Eng.

Salvadori, G., De Michele, C., Durante, F. (2011) On the return period and design in a multivariate framework, Hydrol. Earth Syst. Sci. 15, 3293 - 3305. doi: 10.5194/hess-15-3293-2011. 
Salvadori, G., Tomasicchio, G.R., D’Alessandro F. (2014) Practical guidelines for multivariate analysis and design in coastal and off-shore engineering, Coastal Engineering 88, 1-14. doi: 10.1016/j.coastaleng.2014.01.011.

500 Salvadori, G., Durante, F., Tomasicchio, G.R., D'Alessandro, F. (2015) Practical guidelines for the 501 multivariate assessment of the structural risk in coastal and off-shore engineering, Coastal Engineering 95, 77502 83. doi: 10.1016/j.coastaleng.2014.09.007.

503 Salvadori, G., Durante, F., De Michele, C., Bernardi, M., Petrella, L. (2016) A multivariate Copula-based 504 framework for dealing with Hazard Scenarios and Failure Probabilities, Water Resources Research 52, 3701505 3721. doi: 10.1002/2015WR017225.

506 Salvadori, G., Tomasicchio, G.R., et al. (2020) Multivariate sea storm hindcasting and design: the isotropic 507 buoy-ungauged generator procedure. Sci Reports 10, 20517. https://doi.org/10.1038/s41598-020-77329-y

508 Schölzel, C. and Friederichs, P. (2008) Multivariate non-normally distributed random variables in climate 509 research - introduction to the copula approach, Nonlin. Processes Geophys., 15, 761-772, 510 https://doi.org/10.5194/npg-15-761-2008.

511 Stephens, M. A. (1974) EDF Statistics for Goodness of Fit and Some Comparisons. Journal of the 512 American Statistical Association. 69 (347): 730-737. doi: 10.2307/2286009. JSTOR 2286009

513 Tomasicchio, G.R., Lusito, L., D’Alessandro, F., Frega, F., Francone, A., De Bartolo, S. (2018) A direct 514 scaling analysis for the sea level rise. Stochastic Environmental Research and Risk Assessment. SERR-D-18515 00013R1

516 Trigo, I.F. and Davies, T.D. (2002) Meteorological conditions associated with sea surges in Venice: a 40 years 517 climatology, International Journal of Climatology 22, 787-803. doi:10.1002/joc.719

518 UNESCO/ICOMOS/RAMSAR. (2020) Report of the joint UNESCO/ICOMOS/RAMSAR advisory mission 519 to the World Heritage property 'Venice and its lagoon' (Italy)

520 Yevjevich, V. (1967) An objective approach to definitions and investigations of continental hydrologic 521 droughts, Colo. State Univ., Fort Collins, Colo., Hydrol. Pap. 23 edn. 